\title{
Estudos sobre Alastrim
}

PELO

\author{
Dr. H. de Beaurepaire Aragão \\ (Assistente) \\ (Com a Estampa 18)

\section{Studien über Alastrim} \\ VON \\ Dr. H. de Beaurepaire Aragão \\ Assistenten am Institute \\ (Mit Tafel 18)
}

A denominação de Alastrim, variola mansa, pipoca, varicela, varioloide, milkpox, tem sido dada indistintamente a uma febre eruptiva que ha dois anos para cá, vem grassando em larga escala em varios Estados do Brasil e que é muito semelhante á variola, porém em varios pontos distinta desta molestia.

Ao certo não se póde precizar a data da importação da molestia no Brazil, nem igualmente qual o primeiro ponto do seu territorio que foi invadido. A opinião mais aceita é que o alastrim se implantou primitivamente no Estado da Bahia, localizando-se aí na zona sertaneja das marjens do S. Francisco, donde com a emigração periodica dos habitantes dessas zona's para outros Estados, foi nelles introduzido e hoje grassa profuzamente nos de S. Paulo, Paraná, Santa Catharina, Minas e Goyaz.
Die Namen Alastrim, variola mansa, pipóca, varicela, varioloide, milk-poz sind ohne Unterschied für ein Eruptionsfieber gebraucht worden, welches seit zwei Jahren in grossem Massstab in verschiedenen Staaten Brasiliens grassiert und den echten Pocken sehr ähnlich ist, sich aber in verschiedenen Punkten von denselben unterscheidet.

Der Zeitpunkt der Importation der Krankheit lässt sich ebensowenig sicher bestimmen, wie der Punkt, an welchem dieselbst zuerst in das Gebiet eindrang. Die Ansicht, welche am meisten Anhänger zählt, gibt den Staat BAHIA als zuerst von Alastrim befallen, an, wo es sich in der abgelegenen und wenig kultivierte Ufergebieten des SÃo FrancIsco ausbreitete; von da sei es durch die periodische Auswanderung der Bewohner dieser Zone nach anderen Staaten verschleppt worden, so dass es heute intensiv in S. Paulo, Paraná, Santa Catharina, Minas und Goyaz grassiert. 
Para dar uma idéa das proporções tomadas pela epidemia de alastrim nesses Estados, basta dizer que o numero de cazos, nelles ocorridos, máo grado falhas de estatistica, não é inferior a 250.000 .

Em contraste com esta elevada cifra de cazos aprezenta-se como mais frizante carater do alastrim a sua extrema benignidade. Populações não vacinadas, vivendo em absoluta falta de hijiene, são atacadas pela nova febre eruptiva e não se submetendo a tratamento algum aprezentam diminutissima mortalidade em comparação com o que se sabe em relação á variola entre nós.

Impressionado por estes fatos, o Dr. Emilio Ribas, diretor dos Serviços Sanitarios do Estado de S. Paulo, fez minuciozo estudo clinico do alastrim, e concluiu considerando-o diferente da variola e comparando-o ao Amaas ou Milkpox, que reina na Africa do Sul. Bazeia o Dr. Emilio Ribas as suas concluzões nos seguintes fatos de observação pessoal, hoje fartamente corroborados por quazi todos os clinicos das rejiões atacadas :

I. A baixa mortalidade da molestia que geralmente é de $\mathrm{r} / 2 \%$, ás vezes ainda menor e só raramente excede a $2 \%$. Merece aqui reparo que a maioria dos cazos mortais ocorre geralmente em velhos, pessôas depauperadas por uma cauza qualquer ou portadoras de lezões graves, principalmente nefrites.

2. A menor gravidade nas crianças que nos adultos. $E^{\prime}$ este um fato que uma larga observação corrobora.

$3 .^{\circ}$ Falta de umbelicação da pustula e auzencia da cicatriz deprimida.

$44^{\circ}$ Auzencia da febre secundaria carateristica da variola.

$5 .^{\circ}$ A imunidade pouco duradoura conferida pela molestia para a vacina e vice-versa.
Um eine Idee von der Ausdehnung zu geben, welche die Alastrimepidemie in diesen Staaten gewonnen hat, genügt es zu sagen, dass die Anzahl der beobachteten Fälle trotz grossen Lücken in der Statistik, auf wenigstens 250.000 angeschlagen wird.

Im Gegensatz zu dieser hohen Krankheitszahl steht die für Alastrim besonders charakteristish Benignität. Nicht geimpfte, unter ganz unhygienischen Bedingungen lebende Volksmassen werden von der neuen Eruptionskrankheit befallen und die Mortalität ist, bei Fehlen jeglicher Behandlung, eine ganz geringe, besonders mit derjenigen verglichen, welche hierzulande von den echten Pocken bekannt ist.

Unter dem Eindruck dieser Tatsachen machte Dr. Emilio Ribas, Direktor des Gesundheitswesens des Staats S. PaULO, eingehende Studien über die klinischen Ercheinungen des Alastrim und kam zu dem Schlusse, dass es von Variola verschieden und mit den in Südafrika herrschenden Milk-pox oder Amaas vergleichbar sei. Er stuitzte seine Schlüsse auf die folgenden Fakta eigener Beobachtung, welche heute allgemein durch die Aerzte fast aller befallenen Regionen bestätigt sind :

I. Die niedrige Mortalität, die meist $0,5 \%$ oder weniger beträgt und nur selten $2 \%$ übersteigt. Es verdient bemerkt zu werden, dass die Mehrzahl der Todesfälle Grösse und durch irgend eine Ursache gesundheitlich geschwächte oder an schweren organischen Störungen leidende Personen, besonders Nierenkranke betrifft.

2. Die leichtere Erkrankung von Kindern den Erwachsenen gegenüber, eine durch weitgehende Beobachtungen bestätigte Tatsache.

3. Mangel der Zellenbildung an den Pusteln und Fehlen einer vertieften Narbe.

4. Fehlen eines sekundären Fiebers und des der Variola eigentümliahen Geruchs.

5. Die kurze Dauer der Immunität, Alastrim und Vakzine sich gegenseitig verleihen. 
Estribado nestes fatos, conclue o Dr. E. Ribas que o alastrim é febre eruptiva distinta de todas as demais conhecidas no nosso paiz, e apéla para os laboratorios para que dêm a sua opinião sobre $o$ assunto. Correspondendo aos dezejos manifestados pelo Dr. E. Ribas algumas pesquizas de laboratorio foram feitas entre nós.

O Dr. A. Carini (igio), diretor do Instituto Pasteur de S. Paulo, fez inoculações de material de alastrim na cornea de coelhos e, tendo depois encontrado corpusculos semelhantes aos de GUARNIERI, concluiu pela identidade da doença com a variola, da qual, segundo elle, tambem clinicamente não se distingue senão pela benignidade.

Em trabalho recente o Dr. Max RuDOLPH (I9II), concluindo com o Dr. E. Ribas quanto á natureza da molestia, diz não ter conseguido obter corpusculos de Guarnieri nas corneas de animaes inoculados com alastrim. Filtrando, porém, o material das pustulas, em velas de BERKEFELD e camadas coloidais, conseguiu com o material retido por este ultimo filtro fazer esfregaços que córados pelo Giemsa, deixavam ver corpusculos intensamente córados em vermelho escuro que tambem se córavam pela fuchsina, e que elle comparava aos da vacina e variola, dizendo, porém, que lhe pareceram um pouco mais grosseiros.

Interessando-nos particularmente a questão, rezolvemos fazer sobre $o$ alastrim pesquizas paralelas áquellas, que tinham sido feitas por Prowazek e por nós em relação á variola.

Nosso trabalho foi iniciado em Lassance, no Estado de Minas, aonde grassava a molestia em Novembro de rgro. Nessa localidade, tivemos ocazião de observar não poucos cazos de alastrim e obter material de alguns outros de zonas proximas. Voltando ao Rio, continuámos as nossas pesquizas com o material que trouxemos de Lassance e o proveniente de di-
Auf diese Tatsachen gestützt schloss Dr. Ribas, dass Alastrim von allen andern hier bekannten Eruptionsfiebern verschieden sei und appelliert an das Gutachten der Laboratorien über diesen Gagenstand. Seinen Wünschen entsprechend wurden hier einige Laboratoriumsuntersuchungen gemacht.

Dr. A. CarinI, Direktor des Institut Pasteur in S. PAULO, machte rgro Impfungen mit Alastrimmaterial auf die Hornhaut von Kaninchen und $\mathrm{da}$ er nachher Körperchen fand, welche denen von GUARNIERI ähnlich waren, schloss er auf die Identität der Krankheit mit Pocken, von denen sie sich nach ihm nur durch die Benignität unterscheide.

In einer Arbeit von I9I I kömmt Dr. Max Rudolph die Natur der Krankheit betrefrende zu denselben Schlüssen, wie Dr. E. Ribas und erklärt, dass es ihm nicht gelungen sei, in mit Alastrim geimpften Hornhäuten von Tieren GuarNIERIsche Körperchen zu finden. Wenn er aber das Pustelmaterial durch BERKEFELDfilter und kolloide Schichten filtrierte, gelange es ihm, mit dem zurückgehaltenen Materiale Ausstrichpräparate zu machen, welche nach GIEMSAfärbung intensiv dunkelrot Körperchen zeigten, welche sich auch mit Fuchsin färben liessen; er vergleicht sie mit denjenigen der Vakzine und Variola und sagt, dass sie ihm ewas dicker schienen.

Da ich mich speziell für den Gegenstand interessierte, beschloss ich uber Alastrim Paralleluntersuchungen mit den von ProwazeK und $\mathrm{mir}$ angestellten zu machen.

Meine Studien wurden in Lassance, im Staat Minss, begonnen, wie Alastrim im November I9 Io herrschte. Ich sah an diesen Ort eine nicht geringe $Z$ ahl von Fällen und erhielt Material von einigen andern aus benachbarten Zonen. Nach RIo zurückgekehrt, setzte ich meine Untersuchungen fort, teils mit Material, welches ich von LASSANCE mitgebracht hatte, teils mit solchem, welches ich von verschiedenen Punkten der Staaten Minas, São Paulo und Santa Catharina, sowie von 
versos pontos do Estado de Minas, Santa Catharina e de um doente vindo do $\mathrm{Pa}$ raná que esteve recolhido ao Hospital de S. Sebastião.

Aproveitamos aqui o ensejo para agradecer muito sinceramente aos Drs. Emilio Ribas, Zoroastro de Alvarenga e Guilherme DE Loyola, diretores dos Serviços de Hijiene nos Estados de S. Paulo, Minas e Paraná, e aos companheiros do Instituto, Drs. Adolpho Lutz, Carlos Chagas, Ezequiel Dias, Gomes de Faria, Paulo Horta e A. MaCHADO o inestimavel auxilio que nos prestaram facilitando a observação de doentes e com a remessa de material destinado ao estudo.

Da parte clinica dos cazos por nós observados não nos ocuparemos aqui, pois em nada diverje o que vimos do que é referido pelo Dr. Emilio Ribas. Apenas julgamos util aprezentar algumas fotografias de dous cazos de alastrim que devemos á extrema gentileza do Dr. ZOROASTRO DE Alvarenga (Est. I8, figs. I e 2).

Nosso estudo encarou o seguinte objetivo :

I. ${ }^{\circ}$ A pesquiza do ajente etiolojico por meio de filtrações sobre camadas coloidais.

2. A pesquiza dos corpusculos de GUARNIERI nas corneas inoculadas com puz de alastrim e nas pustulas dos doentes.

$3 .^{\circ}$ Tentativas de reprodução experimental da molestia em coelhos e vitelos, e, si possivel, a sua transformação em alastrim-vacina.

$4 .^{\circ}$ Verificação das associações microbianas nas pustulas.

$5 .^{\circ}$ Verificação da imunidade para a vacina conferida pela molestia no homem $\mathrm{e}$ nos animais de laboratorio, experimentalmente infetados.

O material empregado nestas pesquizas em Lassance foi utilizado imediatamente depois de retirado do doente e no Rio, salvo um doente do Hospital de São Sebastião, foi empregado material velho einem aus PARANÁ Zugereisten erhielt; letzterer war im Hospital São Sebastião interniert.

Ich benutze die Gelegenheit zu aufrichtigem Danke an die Herren Dr. EMILIO Ribas, Zoroastro DE Alvarenga und Guilherme DE Loyola, Direktoren des Gesundheitswesens in den Staaten SÃO Paulo, Minas und Paraná, sowie den Institutskollegen Drs. Adolpho LuTz, Carlos Chagas, Ezequiel Dias, Gomes DE Faria, Horta und A. Machado für die unschätzbare Hilfe, welche sie mir teils durch Gelegenheit zu Krankenbeobachtung, teils durch Zusenden von Studienmaterial gewährten.

Ich werde mich hier nicht mit dem klinischen Teile der von mir beobachteten Fälle befassen, da derselbe sich von dem, von Dr. Ribas geschilderten, nicht unterscheidet. Nur sheint es mir angebracht, auf einer Tafel am Ende dieser Arbeit einige Photographien von zwei Alastrimfällen wiederzugeben; welche ich der Güte des Herrn Dr. Zoroastro de Alvarenga verdanke.

Meine Studien richteten sich nach dem folgenden Plane:

I. Das Aufsuchen des ätiologischen Agens durch Filtration mittelst kolloider Schichten.

2. Das Aufsuchen der Guarnierischen Körperchen in mit Alastrimeiter geimpften Hornhäuten und in den Pusteln der Patienten.

3. Versuche über die experimentelle Reproduktion der Krankheit bei Kaninchen und Kälbern und womöglich ihre Umwandlung in eine Alastrimvakzine.

4. Feststellung der Mikrobienassoziationen in den Pusteln.

5. Feststellung der Immunität, welche die Vakzine für den Menschen und versuchsweise geimpfte Laboratoriumstiere zewährt.

Das Material, welches ich für diese Untersuchungen in LASSANCE verwendete, wurde sofort nach der Entnahme benutzt; in Rio dagegen, von dem Patienten im São Sebastiãospitale abgesehen, gebrauchte ich Material, welches, je nach der 
de alguns dias, conforme a proveniencia, porém cuja ação nos animais de laboratario mostrou não estar atenuado. Uzámos de coelhos e vitelos para as nossas pesquizas de laboratorio.

Passemos agora a referir o rezultado que alcançámos :

I. A pesquiza do microbio no alastrim por meio de filtrações sobre camadas coloidais não é tão facil como na variola, principalmente devido á dificuldade de se obter grande numero delles, visto a sua pouca abundancia. Os primeiros que tivemos ocazião de ver, esses, porém, raros e não permitindo juizo definitivo, foi $\mathrm{em}$ preparações feitas pelo Dr. A. Lutz, em S. Paulo.

Em algumas das filtrações que fizemos foi-nos dado encontrar os microbios em numero consideravel. Aparecem nas preparações córadas pelo metodo de LOEFLER asbolutamente identicos aos da variola e vacina, quer pela forma, quer pelo modo por que se córam. (Est. I8, fig. 3). A fresco aparecem como pequenos corpusculos refrinjentes, dotados de intensos movimentos brozenianos. O Gremsa córa-os mal e tambem mal a fuchsina antes da ação de um mordente qualquer.

Dr. Rudolph afirma ter sempre visto o microbio do alastrim em abundancia nos filtrados e tel-os córado facilmente pela fuchsina e pelo GIEMsa em vermelho escuro; acrecenta que os corpusculos the pareceram mais grosseiros que os da variola. A nós parece, por essas asserções do Dr. Rudolph, que elle obteve a coloração de corpusculos muito frequentes no puz os quais se córam facilmente em vermelho-escuro pelo GIEMSA, e não os verdadeiros microbios do alastrim.

Aqui deixamos assinalados os nossos sinceros agradecimentos ao Dr. MAX RUDOLPH pelos preparados que poz á nossa dispozição para comparal-os com os nossos.

As preparações que tivemos em mão eram córadas pelo Gremsa e já um tanto antigas. Os corpusculos que nellas vimos nos pareceram menos regulares do que os que observámos nos preparados pelo LOEF-
Herkunft, einige Tage alt, aber, nach seinen Wirkungen auf Laboratoriumstiere, nicht abgeschwächt war. Für die Laboratoriumsuntersuchungen verwendete ich $\mathrm{Ka}$ ninchen und $\mathrm{Kälber.}$

Ich gehe jetzt zum Berichte über die gewonnenen Resultate über :

I. Das Aufsuchen der Alastrimmikrobien mittelst Filtration durch kolloide Schichten ist nicht so leicht, wie bei der Variola, besonders wegen der Schwierigkeit, sie in grösserer $Z a h l ~ z u$ erhalten. In Präparaten, welche von Dr. A. Lutz in der Stadt São PAULO gemacht wurden, hatte ich Gelegenheit zuerst solche zu sehen; doch waren sie selten und gestatten kein endgültiges Urteil.

Bei einigen der vorgenommenen Filtrationen hatte ich das Glück die Mikrobien in bedeutender $\mathrm{Zahl} z u$ finden. Sie erscheinen in den nach LaFFLER gefärbten Prepäraten nach Form und Färbbarkeit vollständig denen der Variola und Vakzine gleich. In frischen Präparaten erscheinen sie als kleine glänzende Köperchen mit intensiven Brownschen Bewegungen. Giemsa und Fuchsin, ohne Anwendung einer Beize färben sie schlecht.

Dr. Rudolph versichert die Alastrimmikrobien stets zahlreich in den Filtraten gesehen und sie leicht mittelst GiEms a oder Fuchsin dunkelrot gefärbt $z u$ haben. Es scheint mir nach den Angaben von Dr. RUdOLPH, dass er Körperchen färbte, welche im Eiter sehr häufig sind und sich mit Giemsa und dunkelrot färben, aber nicht die wahren Mikrobien des Alastrim darstellen.

Ich möchte hier Dr. RUdOLPH meinen aufrichtigen Dank für die Präparate ausprechen, welche er mir zum Vergleiche mit den meinigen zur Verfügung stellte.

Die Präparate, welche ich untersuchte, waren nach GIEMSA gefärbt und schon älteren Datums. Die Körperchen, welche ich in denselben sah, schienen mir weniger regelmässig, als die, in den Präparaten nach LGEFFLER beobachteten, was ich der angewendeten Technik zuschrieb; überdies ist die Gremsafärbung für Untersuchungen über Clamidozoen wenig ge- 
FLER o que atribuimos á tecnica empregada, além de que, a nosso vêr, o Giemsa é um máo córante para pesquizas de clamidozoarios, porquanto córa como aquelles microbios granulações ás vezes não especificas.

Em relação á abundancia dos microbios no puz, parece ella estar muito ligada á gravidade do cazo.

2..$^{\circ}$ Quanto á prezença de corpusculos semelhantes aos de GuARNIERI, as nossas pesquizas estão de acordo com as observações de CARINI. Esses corpusculos, expressão da reação provocada pelo germen da molestia no interior da celula parazitada, são encontrados tanto nas corneas dos coelhos, inoculados com puz de alastrim, como nos córtes de pustulas, si bem que em menor numero do que na variola. A auzencia de corpusculos observada pelo Dr. Max Rudolph só póde ser atribuida á tecnica empregada, pois que a obtenção da reação tipica na cornea é sempre facil.

$3 .^{\circ}$ Uma das questões que nos preocupou nas pesquizas que fizemos foi a de adaptar a molestia ao organismo do coelho e de vitelos, e talvez obter um alastrim-vacina. Com o material de varios cazos de alastrim temos já inoculado com rezultado nulo 5 vitelos de menos de ano, seguindo a tecnica habitual empregada para obter vacina nesses animaes. Os numerozos coelhos inoculados sobre a pele do dorso raspada a navalha não têm aprezentado mais que lijeira reação inflamatoria passajeira. A' passajem do virus de cornea a cornea do coelho tem sido negativa, do mesmo modo que inoculações indodermicas com material de corneas infetadas com alastrim.

$4 .^{\circ}$ A pesquiza de microbios no conteudo das pustulas tem-nos mostrado raridade bastante acentuada de estreptococos que só conseguimos izolar de 3 cazos observados em Lassance. Muito comum é a prezença de estafilococos no puz, e, algumas vezes, ao lado delles um pequeno bacilo, tomando a Gram e dando sobre eignet, weil sie manchmal nicht spezifische Granulationen jenen Mikrobien gleich färbt.

Was die Anzahl der Mikrobien im Eiter anbetrifft, so scheint sie in enger Beziehung zu der Schwere des Falles zu stehen.

2. Was das Vorkommen von GuARNIERISchen Körperchen anbetrifft, so ergabien meine Untersuchungen mit den Beobachtungen von CARINI iibereinstimmende Resultate. Diese Körperchen, ein Ausdruck der Reaktion, welche im Innern der befallenen Zellen durch die Krankheitskeime ausgelöst werden, sind sowohl in den Hornhäuten der mit Alastrimeiter geimpften Kaninchen, als in Pustelschnitten zu finden, obschon in geringer $\mathrm{Zahl}$, als bei Variola. Die Abwesenheit der Körperchen, welche von Dr. RUDOLPH beobachtet wurde, kann nur der Technik zugeschrieben werden, da das Hervorrufen der typischen Hornhautreaktion immer leicht ist.

3. Eines der Probleme, die mich bei meinen Untersuchungen beschäftigen, war die Anpassung der Krankheit an den Organismus des Kaninchens und der Kälber, wobei sich vielleicht eine Vakzine gegen Alastrim ergeben hätte. Mit Material von verschiedenen Alastrimfällen habe ich schon fünf Kälber unter einem Jahre nach dem für Erzielung von Vakzine gebräuchlichen Verfahren, aber immer ohne Erfolg, geimpft. Zahlreiche auf die rasierte Rückenhaut geimpfte Kaninchen zeigten nur eine leichte und vorübergehende entzündliche Reaktion. Die Uebertragung des Virus von Hornhaut zu Hornhaut ergab bei den Kaninchen ebensowenig einen Erfolg, als die intrakutane Inokulation mit Material von mit Alastrim geimpften Hornhäuten.

4. Das Aufsuchen von Mikrobien im Pustelinhalt ergab eine ziemlich ausgesprochene Seltenheit der Streptokokken, die ich nur in drei, in LASSANCE beobachteten, Fällen isolieren konnte. Ziemlich häufig. war die Gegenwart von Staphylokokken im Eiter, manchmal in Begleitung eines kleinen Bazillus, der GRAM annahm und 
agar colonias pequenas semelhantes ás do estreptococo.

A raridade do estreptococo no puz das pustulas de alastrim se explica, talvez, pela benignidade das lezões, pelo não enfraquecimento das defezas do organismo contra elle, o que não lhe permite proliferar abundantemente, máo grado a sua prezença na pele. Ao contrario disso, na variola, as lezões mais profundas e intensas e outras condições ainda pouco conhecidas estabelecem um meio nuito favoravel para o dezenvolvimento, donde o fato de ser considerado, germen simbiotico naquella molestia, da qual mais tarde, graças á enorme proliferação e á virulencia adquirida, se torna responsavel pela febre secundaria, septicemias, etc.

$5^{\circ}$ Finalmente, resta-nos tratar da imunidade do alastrim em relação á vacina e vice-versa. Foi o Dr. Ribas o primeiro a chamar a atenção para a pouca duradoura imunidade que é conferida pelo alastrim em relação á vacina. A sua estatistica de 15 cazos de individuos curados ha mais de seis mezes e menos de um ano aprezenta $46 \%$ de rezultados pozitivos. O Dr. Rudolph obteve do oitavo ao decimo mez apoz o alastrim de $27 \%$ de cazos pozitivos de vacinação.

Em Lassance, tivemos ocazião de vacinar I9 individuos que haviam tido a variola mansa ha menos de um ano, obtendo I I cazos de formação de pustulas vacinais, ou seja a proporção de $5^{8} \%$ de rezultados pozitivos. Em relação á imunidade conferida pela vacina, ella é mais eficaz, comtudo o Dr. Ribas cita cazos de pessôas que adquiriram alastrim um e dois anos apóz vacinação pozitiva e o Dr. RuDOLPH assinala igualmente 3 cazos de alastrim em pessôas vacinadas.

O Dr. Loyola igualmente nos assinalou ter observado diversos cazos de alastrim em pessôas vacinadas ha pouco tempo.

Merece aqui especial referencia que nos foi feita pelo nosso colega PaUlo Horta de trez cazos de recidiva do alastrim menos de um ano apoz o primeiro ataque da molestia. As nossas pesquizas auf Agar kleine, denjenigen der Streptokokken ähnliche, Kolonien ergab.

Die Seltenheit des Streptokokkus im Pusteleiter bei Alastrim erklärt sich vielleicht durch die Benignität der Läsionen und die nicht abgeschwächten Verteidigungskräfte des Organismus gegen ihn, was $\mathrm{ihm}$ trotz seines Vorkommens in der Haut keine reichliche Vermehrung gestattet. Im Gegensatz dazu sind bei der Variola die Läsionen tiefgehender und intensiver und andere noch wenig bekannte Bedingungen bieten seinem Fortkommen ein sehr günstiges Medium, weswegen er in jener Krankheit als symbiotischer Keim angesehen und später, dank seiner enormen Vermehrung und erworbenen Virulenz, für das sekundäre Fieber, die Septikämien u. s. w. verantwortlich gemacht wird.

5. Endlich bleibt mir noch übrig die gegenseitige Immunität bei Alastrim und Variola zu besprechen. Dr. Ribas war der erste, welcher die Aufmerksamkeit auf die kurze Dauer der Immunität, die Alastrim gegen Vakzine gewährt, hinlenkte. Seine Statistik von füfzehn Personen, die vor weniger als einem Jahre und mehr als sechs Monaten erkrankten, ergab $46 \%$ positiver Resultate. Dr. RUdOLPH erhielt vom achten bis zum zehnten Monat nach dem Alastrim $27 \%$ positiver Vakzinationserfolge. In LASSANCE hatte ich Gelegenheit 19 Personen zu impfen, welche vor weniger als einem Jahre die milden Pocken gehabt hatten und erzielte in I I Fällen die Bildung von Vakzinepusteln, ein Verhältnis von $5^{8} \%$ Erfolge. Die durch Vakzine verliehene Immunität ist wirksamer, doch führt Dr. Ribas Fälle an, welche Alastrim ein bis zwei Jahre nach erfolgreicher Impfung acquirierten und Dr. Rudolph teilt ebenfalls drei Fälle von Alastrim bei geimpften Personen mit. Auch Dr. Loyola erwähnt drei Fälle, in welchen er Alastrim bei geimpften Personen beobachtete.

Besondere Erwähnung verdient die mir von unserem Kollegen PaULo Horta gemachte Mitteilung über zwei Fälle einer neuerlichen Alastriminfektion, weniger als ein Jahr nach der ersten Erkrankung. 
de laboratorio feitas em coelhos e vitelos, falam tambem em favor da imunidade pouco duradoura conferida pelo alastrim em relação á vacina. Os coelhos inoculados na cornea ou por via cutanea com alastrim, reajem pozitivamente á inoculação de vacina feita 20 a 30 dias depois. Em dois vitelos, nos quais, além de inoculações endodermicas de puz de alastrim, fizemos tambem subcutaneas, de I centimetro cubico do mesmo material, obtivemos, I5 dias depois, pustulas vacinicas tipicas, si bem que em menor numero do que nos vitelos, simplesmente vacinados por via cutanea. Portanto, mesmo a inoculação subcutanea de virus não é suficiente para conferir imunidade contra inoculação posterior de vacina. Por outro lado, dois coelhos inoculados pozitivamente com vacina na cornea aprezentaram 50 dias depois reação pozitiva á inoculação de material do alastrim.

Do que até aqui vimos expondo decorre que o alastrim, embora aprezentando certa semelhança com a variola, é perfeitamente distinto desta, por numerozos aspetos, que lhe outorgam a mais completa autonomia, como tipo morbido.

A benignidade do alastrim, por si só, já é carater distintivo de primeira ordem. Num paiz como o nosso, em que a mortalidade pela variola é sempre elevada, tendo atinjido mesmo em 1908 a proporção de cerca de $60 \%$, deveria cauzar suspeita de não se tratar de variola o aparecimento de vasta epidemia, com mais de 250.000 cazos, em diversos Estados da União, e com uma mortalidade de $\mathrm{I} / 2$ a $2 \mathrm{r} / 2 \%$.

Entre nós ha tempos se deu na Capital do Estado da Bahia uma epidemia de variola benigna, com mortalidade de $4 \%$. A ocorrencia dessa epidemia no Estado da Bahia, onde se acredita tenha primeiro aparecido o alastrim, faz supôr que ella fosse desta ultima molestia. Epidemia que grassou ha tempos em Trindade (I903) parece ter sido igualmente de alastrim, e
Meine, im Laboratorium an Kaninchen und Kälbern gemachten Untersuchungen sf:rechen ebenfalls für die Vakzine verliehenen Immunität. Kaninchen, welche intrakorneal oder subkutan mit Alastrim geimpft sind, reagieren positiv auf die nach $20-30$ Tagen gemachte Vakzinierung. Bei zwei Kälbern, wo ich neben endodermalen Impfungen mit Alastrimeiter auch ein Kubikzentimeter desselben Materiales subkutan einspritzte, erhielt ich I 5 Tage später typische Vakzinepusteln, allerdings in geringerer $\mathrm{Zahl}$, als bei den $\mathrm{K}$ älbern, die bloss in die Haut geimpft wurden. Also ist auch die subkutane Einführung des Virus nicht genügend, um gegen spätere Vakzineimpfung Schutz zu verleihen. Auf der anderen Seite zeigten zwei erfolgreich mit Vakzine intrakorneal geimpfte Kaninchen 50 Tage später positive Reaktion nach Inokulation von Alastrimmaterial.

Aus dem bisher auseinandergesetzten folgt, dass Alastrion zwar eine gewisse Aehnlichkeit mit Variola bietet, von dieser aber in vielen Punkten sich derart unterscheidet, dass ihm als Krankheitstypus völlige Autonomie zukömmt.

Schon allein die Benignität des Alastrim ist ein erstklassiges Unterscheidungszeichen. In einem Lande, wie das unsrige, in welchem die Variolamortalität immer sehr hoch ist und im Jahre 1908 ein Verhältnis von ca. $60 \%$ erreichte, musste das Auftreten einer ausgedehnten Epidemie von mehr als 250.000 Fällen in verschiedenen Staaten der Union mit einer Mortalität von $0,5-2,5 \%$ den Verdacht erregen, dass es sich nicht um Variola handle.

Vor einiger Zeit gab es hier in der Hauptstadt des Staates BAHIA eine Epidemie benigner Variola mit einer Mortalität von $4 \%$. Das Auftreten einer solchen im Staat BaHIA, wo, wie man glaubt, Alastrim zuerst auftrat, lässt vermuten, dass es sich um diese Krankheit handelt. Eine Epidemie, die früher in TRINIDAD (1903) grassiert, scheint ebenfalls Alastrim gewesen zu sein und es ist nicht ganz unmöglich, dass die Epidemie schon in den 
não é de todo impossivel que a doença já tenha grassado nos Estados Unidos (1905), onde tambem já ocorreu uma epidemia de variola benigna.

Com a benignidade do alastrim e com outros carateres semelhantes existem na Africa diversas molestias das quais uma, o Amaas, ou Milk-pox bem descrito por KORTE (I904), aprezenta tais pontos de identidade com elle que, com razão, o Dr. Ribas julga ser a mesma variola mansa que grassa entre nós. Iguais referencias a molestias muito semelhantes á variola fez PleHN no Handbuch der Tropenkrankheiten.

Além da benignidade, ainda outros carateres tornam o alastrim distinto $\mathrm{da}$ variola, tais como: a predileção da molestia para os adultos, a falta de umbelicação das pustulas, a auzencia do máo cheiro carateristico e, sobretudo, como elemento de preponderancia para decidir da questão, as reações de imunidade em relação á vacina, que são duradouras, e tão diversas do que acontece na variola, e isto tanto no homem, como nos animais de laboratorio.

A prezença de microbios semelhantes aos da variola no alastrim e a observação de corpusculos semelhantes aos de GuarNIERI nos córtes de pustulas e nas corneas inoculadas não provam a identidade do alastrim e da variola. $E$ ' sabido que microbios com a mesma morfolojia dos da variola se encontram na vacina, no epitelioma das aves, e nós tambem os temos encontrado na varicela. Por outro lado, existem ainda em outras doenças devidas aos clamidozoarios. Recentes pesquizas de Bertarelli (ig09), Keysselitz e Meyer (I909) e de Levaditi (I9II) provam que tambem na varicela se encontram corpusculos semelhantes aos de GuARNIERI, e ninguem por isso considera a varicela variola vera.

Que a variola, o alastrim e a varicela tenham filiação comum é perfeitamente admissivel; com o correr do tempo,
Vereinigten StaAten (ig05) geherrscht hat, wo auch schon eine sehr milde Pockenepidemie beobachtet wurde.

In AFriKa kommen verschiedene Krankheiten vor, die in ihrer Gutartigkeit und anderen Eigentümlichkeiten dem Alastrim ähnlich sind und eine derselben, die von KORTE (1904) gut beschrieben und als Amaas oder Milk-pox bekannt ist, zeigt mit demselben eine so weit gehende Uebereinstimmung, dass sie Dr. Ribas mit Recht für identisch mit der hier herrschenden milden Pockenform hält. Auch PlehN erwähnt im Handbuch der Tropenkrankheiten solche der Variola sehr ähnliche Krankheiten.

Ausser durch die Gutartigkeit unterscheidet sich Alastrim noch durch andere Charaktere von den Pocken, wie die Vorliebe der Krankheit für die Erwachsenen, die mangelnde Dellenbildung bei den Pusteln, das Fehlen des charakteristischen Geruches, endlich, als ein Hauptelement für die Entscheidung der Frage, die Immunitätsreaktionen in Beziehung zur Vakzine, die kurz dauern und ganz verschieden von denjenigen bei $\mathrm{Va}$ riola sind, gleichviel, $o b$ es sich um Menschen oder Laboratoriumstiere handelt.

Das Vorkommen von denjenigen der Variola ähnlichen Keimen bei Alastrim und von Körperchen, die denjenigen Guarnieris's gleichen, in Pustelschnitten und geimpften Hornhäuten sind kein Beweis für die Identität beider Prozesse. Es ist bekannt, dass morphologisch uibereinstimmende Mikrobien bei Vakzine und Epitheliom der Vögel vorkommen und ich habe sie auch bei Varizellen gefunden. Neuere Untersuchungen von BERTARELLI (I909), Keysselitz und Meyer (I909), sowie von LEVADITI (IgIr) beweisen, dass bei Varizella ebenfalls den GuARNIERI'schen ähnliche Körperchen gefunden werden und doch hält niemand deswegen die Varizellen für identisch mit der Variola vera.

Dass Variola, Alastrim und Varizellen gemeinsamer Abstammung sind, ist ohne Weiteres zuzugeben; sie haben sich jedoch im Laufe der Zeit hinreichend 
porém, ellas se diferenciaram bastante, para adquirir autonomia completa como tipos morbidos. Para ellas se deve criar o grupo variolico, como hoje é por todos admitido o grupo tifico. Este grupo é, como se sabe, constituido por doenças ás vezes clinicamente semelhantes e que são cauzadas por bacterios morfolojicamente identicos, com carateres culturais muito proximos ou mesmo identicos (para-tifos, Bacillus enteritidis de GARTNER e GüNTHER, e typhi murium), com reações de imunidade comuns (coaglutinações, etc.) e, cuja intensidade, ás vezes, é tão pronunciada que se torna impossivel, sómente por ellas, fazer diagnostico diferencial seguro.

Ora, si o grupo tifico é hoje universalmente aceito, com igual direito e com bazes seguras póde estabelecer-se um grupo variolico constituido, desde já, pela variola, como tipo e por duas para-variolas, o alastrim e a varicela. Estamos carto que ainda outras doenças para-variolicas se virão juntar a estas, a julgar pelas referencias de Korte e Plehn.

Manguinhos, I2 - 91 I. differenziert, um als völlig unabhängige Krankheitstypen zu gelten. Man muss für dieselben eine Variolagruppe aufstellen, wie heute schon allegemein eine $\mathbf{T y}$ phusgruppe anerkannt wird. Diese besteht, wie bekannt, aus Krankheiten, die sich öfters klinisch gleichen und durch in ihrer Form übereinstimmende Bakterien verursacht werden, deren Kultureigentümlichkeiten sehr ähnlich oder völlig gleich sind (Paratyphus $B$. enteritidis von Gaertner sund Guenter und typhus murium) und gemeinsame Immunitätsreaktionen (Koagglutinatination) besitzen, die oft derart ubereinstimmen, dass man aus ihnen allein keinen Artunterschied erkennen kann.

Wenn nun die Typhusgruppe allgemein anerkannt wird, kann man mit demselben Rechte und zur sicherer Basis eine Variolagruppe aufstellen, welche bereits die Variola als Typhus und zwei paravariolöse Formen, Alastrim und Varizella besitzt. Nach den Angaben von Korte und Plehn glaube ich sicher, dass sich diesen noch andere paravariolöse Prozesse anschlissen werden.

Manguinhos, I2 - 9rI. 

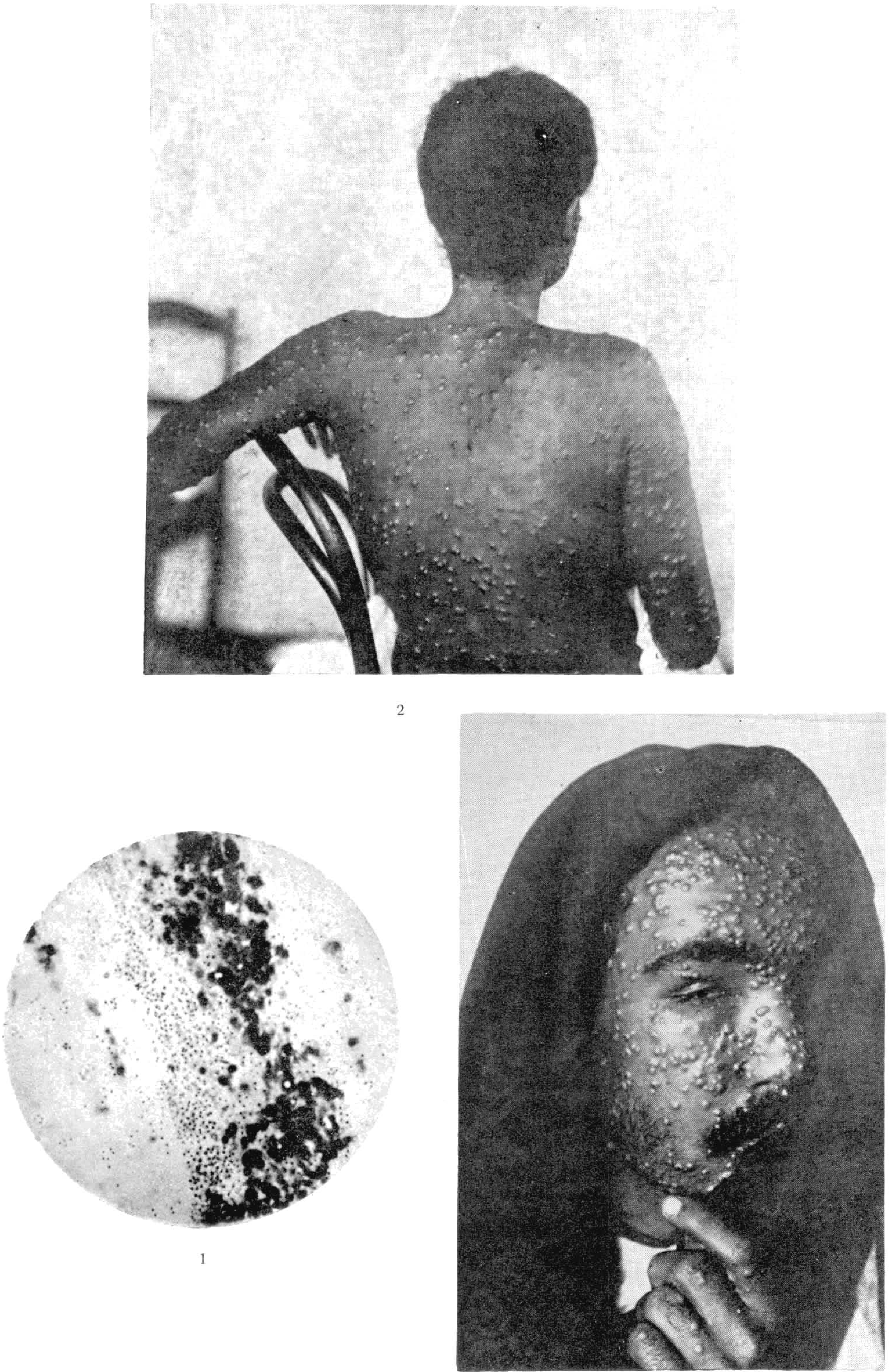


\section{BIBLIOGRAFIA.}

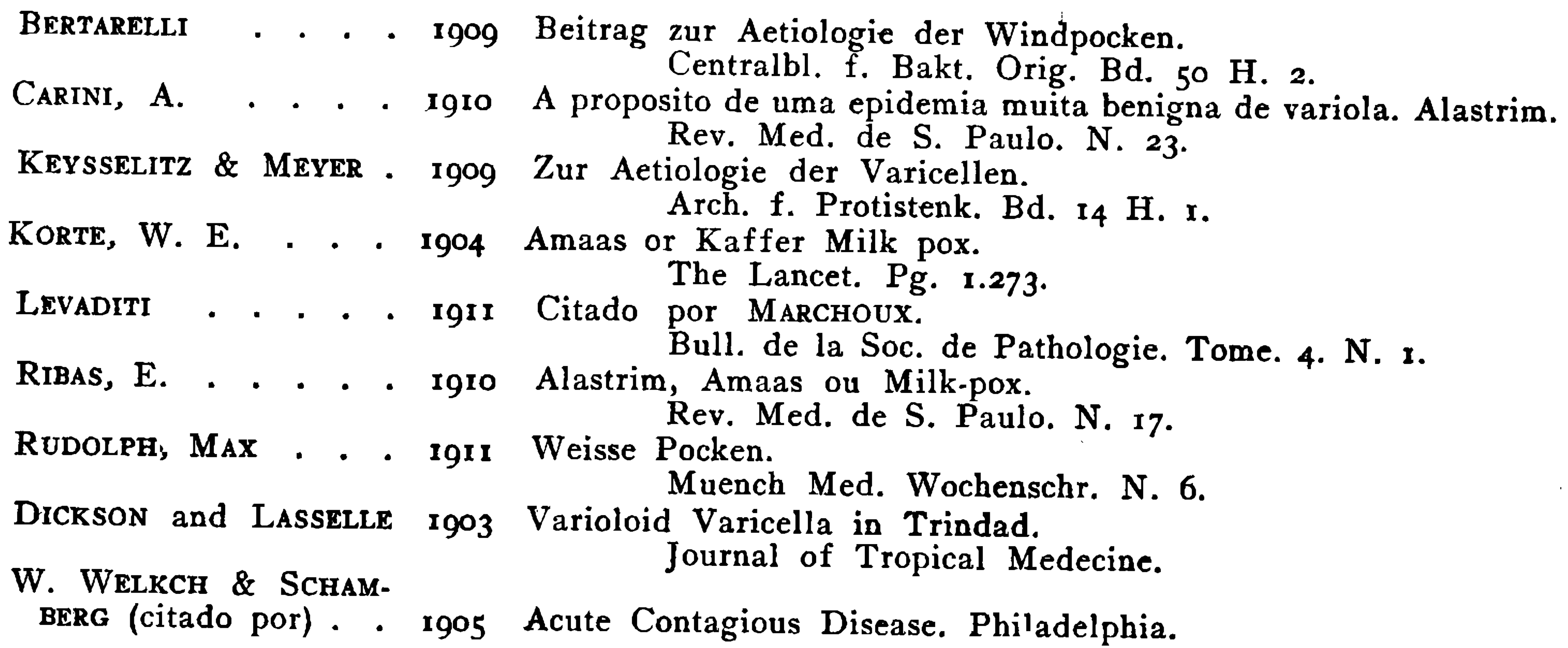

\section{EXPLICAÇÃO DA ESTAMPA 18} Figs.

I e 2 - Dous doentes aprezentando a erupção de alastrim.

3 - Fotomicrografia do microbio do alas. trim. Esfregaço do conteúdo da pustula. Coloração pelo metodo de Loeffler. Aumento: Ocul. comp. 12, obj. apocr. 2 mm.
ERKLAERUNG DER TAFEL I8 Fig.

I u. 2-Zwei Patienten mit Alastrim im Eruptionsstadium.

3 - Photomicrographie des Organismus der Alastrim. Pustelausstrich nach Loeffler gefärbt. Compens. Oc. 12, Qbj. Apochr. 2 mm. 